\title{
O ensino de línguas estrangeiras no Brasil e a "compreensão do estrangeiro": o papel da tradução
}

\author{
Ruth Bohunovsky (BOHUNOVSKY, Ruth) \\ Professora Doutora da Universidade Federal do Paraná - UFPR \\ ruth.bohunovsky@uol.com.br
}

\section{Resumo}

A tradução está perdendo o estigma de não combinar com o ensino/aprendizagem de uma língua estrangeira. Porém, ainda há poucas reflexões sobre os diferentes usos didáticos e metodológicos da tradução nesse contexto. O Quadro Europeu Comum representa uma base interessante, entretanto limitada, para se pensar sobre o papel da "mediação linguística" no ensino de línguas estrangeiras no Brasil. Neste artigo, discutimos as diferenças entre a situação europeia na qual e para a qual o Quadro foi desenvolvido e o contexto brasileiro onde esse documento vem ganhando influência. Partindo da definição da "compreensão do estrangeiro" - nos moldes teóricos propostos por Claus Altmayer (2004) - como sendo um objetivo didático, discorremos sobre o uso de atividades tradutórias num sentido mais amplo do que o proposto no Quadro, levando em consideração as especificidades brasileiras de ensino. Com base nessa discussão, sugerimos reflexões e pesquisas mais abrangentes sobre a complexidade do ato tradutório e os benefícios da tradução no ensino de línguas estrangeiras no nosso país.

Palavras-chave: tradução, ensino de línguas estrangeiras, competência cultural.

\begin{abstract}
Abstract

Translation has been losing its stigma of not fitting into teaching of foreign languages. Yet scant consideration has been given to the different didactic and methodological uses of translation in this context. The Common European Framework represents an interesting - if limited - basis for discussion about the role of "linguistic mediation" in foreign language teaching in Brazil. This paper analyzes the differences between the European situation where the Framework was developed and the Brazilian context where this document is progressively becoming more influential. On the basis of the concept of "comprehension of the foreign" - suggested by Claus Altmayer (2004) - as a didactic goal, we propose the application of translation activities in a wider sense than that envisaged by the Framework. Finally, we suggest further studies and research about the useful roles of translation in foreign language teaching in our country.
\end{abstract}

Keywords: translation, foreign language teaching, cultural competency. 


\section{Introdução: dialogar sem esquecer as diferenças}

A prática de ensino/aprendizagem de línguas estrangeiras no Brasil tem se orientado muito, desde sempre, naquilo que tem sido dito e pesquisado sobre esse assunto em outros países, especialmente nos países das respectivas línguas alvo. Um exemplo atual dessa receptividade em relação a propostas didáticas alheias é a grande influência que o Quadro Europeu Comum de Referência para as Línguas Aprendizagem, Ensino, Avaliação tem exercido, nesses últimos anos, no ensino/aprendizagem de línguas estrangeiras no Brasil - um país que não se encontra no Velho Continente e que, consequentemente, não faz parte do contexto políticolinguístico para o qual e no qual o Quadro foi desenvolvido. Com isso, não pretendo sugerir que o Quadro não possa ser um ponto de referência ou uma base útil também para o ensino de línguas estrangeiras no nosso país. Mas, acredito que uma discussão sobre o possível ou desejável papel que o Quadro deveria assumir no Brasil não deveria partir, por exemplo, da pergunta feita por Carmen Praxedes (2008) no subtítulo de um artigo seu sobre o Quadro: "o que falta ao Cone Sul para seguir este exemplar modelo de integração multicultural?" Deveríamos sim perguntar: em que medida o Quadro pode ser relevante para o ensino de línguas estrangeiras no Brasil? Ou seja, se percebermos que, no Quadro, haja sugestões didáticas não condizentes com a situação de ensino brasileira, isso não deve necessariamente nos conduzir à conclusão de que "falte" algo aqui, ou de que talvez ainda não tenhamos chegado onde se encontram os europeus hoje. Devemos, sim, concluir que há diferenças significativas entre as condições de ensino de línguas estrangeiras na Europa e no Brasil e que essas diferenças precisam ser levadas em consideração na hora de se pensar sobre esse tipo de ensino em nosso país - pois, como diz a própria Praxedes (2008), não queremos "primar por uma prática implantacionista da verdade Européia à nossa realidade”.

Ao se refletir sobre a prática de ensino/aprendizagem de línguas estrangeiras no Brasil a partir de teorias linguísticas e didáticas que vêm de um outro contexto geográfico e político, corre-se o risco de ignorar certos aspectos que devem ser considerados para o Brasil e que talvez mereçam mais atenção. Se pensarmos, por exemplo, no ensino de aspectos fonéticos, podemos imaginar que um material específico que apresente as dificuldades típicas de pronúncia do aprendiz brasileiro possa ser mais útil para o ensino do que o grande número de exercícios que 
encontramos, às vezes, em livros didáticos importados, devido à concepção genérica desses últimos. Quanto ao ensino/aprendizagem do alemão, já discuti, em trabalhos anteriores, outros aspectos potencialmente críticos do uso de livros didáticos preparados para o mercado internacional e seu uso no Brasil (cf., por exemplo, BOHUNOVSKY, 2005). Em relação ao diálogo intercultural, visto como um objetivo central para o ensino de uma língua estrangeira, vale a pena também lembrar a argumentação de Rosvitha F. Blume (1997). Na sua dissertação de mestrado sobre a obra didática internacional Themen Neu, a autora chega à conclusão de que esse material "não enfoca suficientemente a questão do encontro entre culturas", pois "o aluno, sua realidade, sua maneira de compreender ficam muito à margem da obra” (1997, p. 83). Portanto, embora reconhecendo que muito que vem de fora possa ser vantajoso para a prática e a teoria do ensino aqui no Brasil, é fundamental pensar nas especificidades desse ensino no nosso contexto e levá-las em consideração no momento de planejamento de aula e na escolha de material didático.

Com base nessas premissas, gostaria de fazer algumas reflexões sobre o papel que a tradução poderia desempenhar no ensino de línguas estrangeiras. Para isso, parto da minha percepção da realidade da área de alemão, mas acredito que haja muitas semelhanças com as áreas de outras línguas. Começo minha argumentação com alguns comentários sobre o papel da tradução proposto no Quadro Europeu Comum e, depois, procuro argumentar que, no Brasil, a tradução poderia cumprir papéis variados e, em parte, diferentes daqueles que se colocam como sendo relevantes para o ensino de línguas estrangeiras (e segundas línguas) no contexto europeu.

\section{A tradução no Quadro Europeu Comum}

No Quadro Europeu Comum, a tradução ganhou espaço na forma de "mediação linguística". A "mediação" é definida como uma das quatro atividades linguísticas, ao lado da produção, da recepção e da interação. De um modo geral, pode-se constatar que, embora com funções e justificativas diferentes daquelas de outros momentos na história da teoria do processo de ensino/aprendizagem, a tradução constitui hoje uma componente considerada relevante no ensino de línguas estrangeiras. Sem dúvida, encerrou-se a fase da "estigmatização e eliminação da tradução das salas de aula sob a 
acusação de não ser comunicativa" (HARGREAVES, 2004, p. 47). Cada vez mais, estão sendo discutidas as diferentes funções que as atividades tradutórias poderiam ter no contexto do ensino de línguas estrangeiras (cf., por exemplo, a revista especializada no ensino de alemão como segunda língua/língua estrangeira Fremdsprache Deutsch: Übersetzen im Deutschunterricht, 2000).

Com a denominação "mediação linguística", diferencia-se esse conceito do que seria uma competência tradutória profissional. Por "mediação linguística" entende-se no Quadro Europeu Comum, de um modo geral, a tradução oral e escrita, assim como a atividade de resumir um texto em outra língua (GLABONIAT et al., 2005, p. 59). Já que o Quadro parte da premissa de que "apenas o contexto social confere significado pleno às atividades linguísticas" (GLABONIAT et al., 2005, p. 60), torna-se óbvia a orientação dos exemplos nele listados pela comunicação cotidiana e oral. Isso se explica pela situação vivida pela maioria dos europeus hoje em dia, ou seja, um contato quase diário com pessoas que falam outras línguas. Em muitos livros didáticos produzidos na Alemanha, encontramos, por exemplo, propostas de exercícios e tarefas em sala de aula que visam exatamente a uma competência desse tipo.

Para ilustrar essa orientação na comunicação cotidiana e na ação comunicativa, cito alguns exemplos do que seria a competência de mediação linguística que o Quadro define para os diferentes níveis:

- [O falante] consegue transmitir rudimentarmente informações importantes e esperadas de textos orais curtos em alemão sobre temas familiares e cotidianos, faladas na língua padrão, para outras pessoas na língua comum ${ }^{1}$ (nível A2) (GLABONIAT et al. 2005, p. 126);

- [O falante] consegue transmitir num resumo as declarações e pontos de vista importantes de complexos textos orais [ou escritos] em alemão da área de interesse e conhecimento próprio para outras pessoas da língua comum $^{2}$ (nível B2) (GLABONIAT et al. 2005, p. $168)$;

- [O falante] consegue, numa conversação cotidiana entre pessoas de língua alemã e outras que não falam alemão, transmitir mutuamente todos os conteúdos e todas as informações de maneira completa,

\footnotetext{
${ }^{1}$ Texto original: Kann wichtige, erwartbare Informationen aus kurzen mündlichen deutschsprachigen Texten zu alltäglichen und vertrauten Themen, die deutlich in Standardsprache gesprochen werden, in groben Zügen anderen Personen in der gemeinsamen Sprache weitergeben.

${ }^{2}$ Texto original: Kann wichtige Aussagen und Standpunkte komplexerer mündlicher [schriftlicher] deutscher Texte aus dem eigenen Fach-oder Interessensgebiet anderen Personen in der gemeinsamen Sprache zusammenfassend weitergeben.
} 
clara, fluente e estruturada ${ }^{3}$ (nível C2). (GLABONIAT et al., 2005, p. 211)

Apesar do peso atribuído à mediação linguística no Quadro, na prática europeia, muitas vezes a tradução nas suas diversas formas metodológicas não ocupa muito espaço, devido ao fato de que há frequentemente grupos de aprendizes muito heterogêneos (com várias línguas maternas). Sabine Dengscherz, num artigo recente sobre o ensino de alemão como segunda língua, publicado na revista ÖDaFNachrichten, destaca, por exemplo, que a "comparação entre as línguas" tem ocupado um lugar de "pouca importância" até o presente momento. A autora define como um motivo para essa desatenção o fato de que, "muitas vezes, os professores têm que trabalhar com grupos heterogêneos, em que muitas línguas são faladas [e] assim parece difícil encontrar uma base de comparação comum” (DENGSCHERZ, 2008, p. 51). Já que a autora acredita que a comparação entre a língua materna dos aprendizes e a sua segunda língua (e o mesmo vale, sem dúvida, para uma língua estrangeira) possa trazer muitos benefícios (entre outros, a competência intercultural e a consciência linguística) (DENGSCHERZ, 2008, p. 49), ela apresenta alguns exemplos didáticos para a comparação linguística e, também, "exercícios tradutórios" a serem trabalhados mesmo em grupos heterogêneos (2008, p. 52).

\section{A tradução no ensino de línguas estrangeiras no Brasil}

No que concerne à área de alemão, pode-se fazer a seguinte observação (provavelmente válida para várias outras línguas estrangeiras estudadas no Brasil), que é pertinente no contexto deste trabalho: uma grande parte das pesquisas, das teorias de ensino/aprendizagem e do material didático produzido nos países de língua alemã refere-se ao ensino/aprendizagem de alemão como segunda língua. Mas, o ensino de alemão no Brasil acontece na modalidade de língua estrangeira, em circunstâncias diferentes. Consequentemente, a "importação" de ideário e de material didático produzido na Europa deve ser feita com as devidas adaptações.

\footnotetext{
${ }^{3}$ Texto original: Kann in einem Alltagsgespräch zwischen deutschsprachigen und anderssprachigen Personen alle Inhalte und Informationen vollständig, klar, flüssig und strukturiert wechselseitig wiedergeben.
} 
Apesar de haver diferenças significativas de idade, origem social, motivo de aprendizagem entre os grupos de aprendizes e/ou contextos institucionais diversos, podemos presumir que em praticamente todos os cursos de língua estrangeira no nosso país, os alunos falam português como primeira língua - ou seja, existe uma língua comum ao professor e aos aprendizes. Além disso, diferentemente do que ocorre com frequência no contexto europeu, os aprendizes brasileiros têm geralmente poucas oportunidades no seu dia a dia de pôr em prática suas habilidades de mediação linguística, isto é, de usar seus conhecimentos e habilidades na língua estrangeira para estabelecer a comunicação entre duas pessoas que não têm uma língua em comum. Desse modo, aquilo que se reveste de grande importância para se pensar sobre a tradução em sala de aula nos países europeus - a frequente falta de uma língua comum a aprendizes e professores e, ao mesmo tempo, as muitas possibilidades de uma "mediação linguística" no dia a dia dos aprendizes -, evidencia-se como um fator não relevante no contexto brasileiro.

Ao se tratar da tradução no ensino de línguas estrangeiras, faz-se necessária uma reflexão teórica um pouco mais aprofundada do que aquela que rege o senso comum. Antes de mais nada, deve-se distinguir os diferentes usos metodológicos dessa atividade em sala de aula, tais como: primeiro, a compreensão da tradução como uma habilidade comunicativa e pragmática e como preparação para ações comunicativas "culturalmente adequadas" (GLABONIAT et al., 2005, p. 83) que visam, sobretudo, a evitar malentendidos culturais no cotidiano do país da língua estudada - como proposto pelo Quadro Europeu Comum; segundo, o uso do termo "tradução" para se referir ao uso da língua materna para explicar e semantizar vocabulário estrangeiro; terceiro, a tradução de frases isoladas com o fim de aprendizagem ou testagem de aspectos gramaticais ${ }^{4}$; e, finalmente, a possível função da atividade tradutória em sala de aula - ou a comparação de versões diferentes de um mesmo texto de partida - tendo como objetivo principal a "aprendizagem crítico-reflexiva", concentrando-se em aspectos linguísticos e/ou culturais.

Como pretendo argumentar a seguir, é nesse último uso didático que a tradução poderia cumprir uma função importante no ensino de uma língua estrangeira para grupos de aprendizes linguisticamente homogêneos e que se encontram distantes dos

\footnotetext{
${ }^{4}$ Cf. também Welker (2004), que distingue claramente entre o uso da língua materna em sala de aula e a tradução de frases isoladas.
} 
países onde sua língua alvo é a língua oficial. Por um lado, por razões óbvias, uma concentração exclusivamente em exercícios de mediação que visam a tradução oral sobre temas do cotidiano não se justifica no contexto brasileiro. Por outro lado, a leitura aprofundada que antecede e acompanha qualquer tradução, assim como as possíveis discussões que interpretações divergentes de termos e textos estrangeiros podem gerar em sala de aula durante o processo tradutório podem ser vistas como excelentes oportunidades de melhorar a "compreensão do estrangeiro" - um objetivo importante no ensino de línguas estrangeiras, como discutirei mais adiante.

Antes de enfocar esse ponto, gostaria de chamar a atenção para um fato: as definições de competência de mediação linguística que encontramos no Quadro Europeu Comum - algumas das quais citei num parágrafo acima - baseiam-se claramente numa compreensão teórica de tradução que, há décadas, está sendo colocada em questão por pensadores e teóricos da área. Se, entre os teóricos, discute-se a complexidade de qualquer atividade tradutória - sempre com o afloramento de questões de interpretação, cultura, poder, gênero, construção de significados, aspectos pragmáticos etc. -, nas descrições no Quadro, a tradução parece estar reduzida a uma mera transposição de significados supostamente implícitos no texto; pois apenas a premissa de que um texto possa encerrar um "conteúdo" e "informações" claramente definíveis permite requerer a "transmissão" dos mesmos. Assim, no Quadro, a tradução parece ser entendida segundo as categorias do senso comum, e sua alta complexidade fica simplificada a uma habilidade supostamente técnica. No entanto, se partimos do pressuposto de que a tradução nunca é um transporte de significados, mas uma atividade interpretativa de alta complexidade, ampliam-se as possibilidades e vantagens das atividades tradutórias em sala de aula de língua estrangeira. Nesse sentido, é, sobretudo, o processo tradutório - e não o produto - que nos parece relevante, considerando-se a “compreensão do estrangeiro" um objetivo do ensino/aprendizagem de língua estrangeira.

\section{A compreensão do estrangeiro no ensino de língua estrangeira}

O estudo de aspectos culturais é considerado, há muito tempo, uma componente importante do processo de ensino/aprendizagem de uma língua estrangeira, mas a 
compreensão daquilo que constituiria o conteúdo ou o objetivo de tal estudo tem sofrido muitas mudanças. No final do século XIX e nas primeiras décadas do século XX, a aquisição de um conhecimento enciclopédico relativo ao país da língua estrangeira era entendida como sendo o seu objetivo principal. Após a Primeira Guerra Mundial, a partir de uma compreensão humboldtiana de unidade entre língua, cultura e nação, definiu-se que a meta do estudo de aspectos culturais seria a "exploração do mundo espiritual estrangeiro através da compreensão dos bens culturais manifestos na língua estrangeira e, com isso, a compreensão da própria cultura" (OTTO, 1925, p. 365, apud LEUPOLD, 2007, p. 129). Essa abordagem - que já implicava uma comparação do próprio com o outro - estava baseada numa visão hierárquica entre culturas nacionais para servir a diversos interesses políticos. Depois do paradigma estruturalista nos anos 1960, que focalizava seus interesses nas estruturas linguísticas e em teorias behavioristas de aprendizagem, o ensino de aspectos culturais ganhou novo peso e uma redefinição nos anos 1970, com o crescente interesse na competência comunicativa e intercultural dos aprendizes.

Nos últimos anos, têm surgido algumas abordagens teóricas que compreendem a competência intercultural como um conceito que deve ir além de fins meramente pragmáticos - como, por exemplo, o ensino de meios comunicativos para se comportar com adequação cultural em situações cotidianas como cumprimentos, apresentações, despedidas, agradecimento etc. (GLABONIAT et al., 2005, p. 83). Nesse sentido, Claus Altmayer (2004) - um teórico de destaque na área do ensino de alemão como língua estrangeira - critica o uso indiscriminado do termo "competência intercultural" por considerá-lo vago demais e por estar voltado para o ensino prático e utilitarista de possíveis maneiras de se evitarem mal-entendidos e complicações (ALTMAYER, 2004, p. 37-38). Baseando-se principalmente na teoria da ação comunicativa de Jürgen Habermas (1981) e num conceito de cultura aberto (a cultura vista como "hipertexto"), ele define como objetivo central do ensino/aprendizagem de aspectos culturais a “compreensão do estrangeiro".

É importante ressaltar que, para Altmayer, o termo "compreensão" não remete à ideia de um suposto "resgate" de significados ou conteúdos de um outro. Portanto, não entendemos aqui "compreensão" como antônimo de "interpretação" 5 . Segundo Altmayer, 'a 'compreensão', num sentido normativo da hermenêutica reformulada pela

${ }^{5}$ Para uma discussão mais aprofundada sobre esses dois conceitos, cf. Arrojo (1992). 
teoria de comunicação, remete a um processo sempre interminável de comunicação/entendimento" (ALTMAYER, 2004, p. 67). Para os fins do ensino/aprendizagem de línguas estrangeiras, faz-se necessário, de acordo com Altmayer, um conceito normativo de compreensão que permita uma diferenciação entre certo e errado. Tal diferenciação não se encontra na materialidade do texto, nem nas intenções do autor ou em interpretações consagradas, mas no diálogo entre o leitor e essas outras instâncias. O que - conforme as premissas teóricas do construtivismo seria uma "compreensão" (o processo cognitivo de construção de um significado coerente e subjetivamente satisfatório pelo sujeito) poderia, portanto, ser visto como algo errado num sentido normativo-hermenêutico ${ }^{6}$. Para uma compreensão considerada correta nesse contexto teórico, o leitor deve estar dialogando e conhecendo, na medida do possível (pois esse conhecimento jamais será completo ou concluído, nem para falantes nativos), o conhecimento de fundo, pressuposto necessário para uma leitura apreensível pela comunidade interpretativa e para poder justificar sua interpretação. Um dos objetivos de uma análise textual no ensino/aprendizagem de língua estrangeira deveria ser, portanto, tornar mais explícito tal conhecimento sociocultural. Certo e errado não seriam características válidas para sempre ou determináveis de um modo dogmático, mas construídas e negociadas no diálogo - sem diálogo, não há compreensão.

Em relação especificamente à "compreensão do estrangeiro" no contexto do processo de ensino/aprendizagem de língua estrangeira, Altmayer faz ainda as seguintes observações, relevantes para a nossa argumentação:

A “compreensão do estrangeiro" no sentido de uma relação significativa, orientada pelo entendimento, com textos, enunciados ou, de um modo geral, com ações comunicativas de uma outra comunidade linguística e comunicativa não é, portanto, sinônimo de "empatia" ou a ocupação de uma perspectiva "estrangeira" com a concomitante suspensão do "próprio"; a "compreensão do estrangeiro" também não é equivalente à "compreensão" no sentido de um acordo preconcebido, segundo o qual tudo que é "estrangeiro" seria valioso pelo simples fato de ser "estrangeiro". A compreensão do estrangeiro é, muito mais, uma discussão crítica que, por um lado, parte da premissa de que a ação comunicativa do outro seja, a princípio, uma ação racional que tem sentido e que, talvez, tenha algo importante a me dizer, mas em cujo percurso possa-se evidenciar que

${ }^{6}$ Para ilustrar esse fato, Altmayer se refere ao conto Kannitverstan, de Johann Peter Hebel (ALTMAYER, 2004, p. 43). 
essa expectativa era infundada. E, finalmente, a compreensão do estrangeiro é, por si só, uma ação comunicativa [...] que não pode, em momento algum, chegar a uma conclusão definitiva. ${ }^{7}$ (ALTMAYER, 2004, p. 71)

Além de destacar a importância de diversas subcompetências da "compreensão do estrangeiro" "8 no âmbito do ensino/aprendizagem de língua estrangeira, Altmayer define também o "conhecimento cultural" como importante para a "compreensão" pretendida. Tal "conhecimento cultural" não seria um conhecimento global estereotipado sobre a "cultura" da língua estrangeira, mas uma construção (interminável) de "padrões culturais de interpretação" (kulturelle Deutungsmuster) determinantes e significantes para uma comunidade comunicativa (ALTMAYER, 2004, p. 76-77).

Uma vez definida a compreensão do outro, nos moldes teóricos expostos, como um objetivo do ensino de línguas estrangeiras, passo agora a refletir sobre a possível utilidade de textos "autênticos" na língua alvo e sua leitura e/ou tradução para alcançar esse objetivo. Herbert Christ parte da concepção de que, no ensino de línguas estrangeiras, o processo da compreensão do estrangeiro pode se dar em três níveis: no contato com a estrutura da língua estrangeira em si, com pessoas que falam a língua estrangeira e com textos escritos nessa língua (2007, p. 53). Já Altmayer - referindo-se à metáfora "cultura como texto", de Clifford Geertz - ressalta que são primordialmente os textos escritos que permitem o "acesso" a uma cultura (2004, p. 11). Embora prefiramos os termos "interpretação", "diálogo" ou "construção de uma relação" - em

\footnotetext{
${ }^{7}$ Texto original: 'Fremdverstehen' im Sinne eines verstehenden, an Verständigung orientierten Umgangs mit Texten, Äußerungen oder ganz allgemein mit kommunikativen Handlungen einer anderen Sprachund Kommunikationsgemeinschaft ist also nicht gleichzusetzen mit 'Empathie' oder dem Einnehmen einer 'fremden' Perspektive bei gleichzeitiger Suspendierung des 'Eigenen'; 'Fremdverstehen' ist auch nicht gleichzusetzen mit 'Verständnis' etwa im Sinne eines vorgängigen Einverständnisses, wonach alles 'Fremde` allein deswegen als wertvoll anzusehen wäre, weil es 'fremd' ist. Fremdverstehen ist vielmehr ein Prozess der auch kritischen Auseinandersetzung, der zwar von der Erwartung ausgeht, dass die kommunikative Handlung eines 'Fremden' eine prinzipiell rationale und sinnvolle Handlung ist und mir möglicher Weise etwas Wichtiges zu sagen hat, in dessen Verlauf sich diese Erwartung aber auch als unbegründet erweisen kann. Und nicht zuletzt handelt es sich beim Fremdverstehen selbst wiederum um eine kommunikative Handlung [...], die also nicht an irgendeiner Stelle einen definitiven Abschluss finden kann.

${ }^{8}$ Referindo-se especificamente ao ensino de línguas estrangeiras, Carola Surkamp (2007, p. 138) apresenta, por exemplo, um panorama detalhado sobre essas diversas subcompetências necessárias para se chegar a uma compreensão satisfatória do estrangeiro: 1) as competências afetiva e social (constituídas pela disposição para compreender o outro, pela autoconfiança e a tolerância); 2) as competências de conteúdo, linguísticas e comunicativas (constituídas por conhecimentos sobre o país da língua alvo, a compreensão e habilidade oral na língua estrangeira e o uso da língua estrangeira em situações de comunicação concretas); 3) as competências interculturais (constituídas, entre outras componentes, pela conscientização da própria posição, a diferenciação e mudança de perspectivas); e 4. as competências reflexivas (coordenação de perspectivas e consciência cultural).
} 
vez de "acesso" -, entendemos que a comunicação intercultural ocorre também na leitura de textos e não apenas no contato interpessoal com falantes nativos da língua estrangeira, já que a leitura - assim como qualquer outro tipo de comunicação e compreensão - não se reduz a uma recepção neutra de significados supostamente intrínsecos ao texto, mas é sempre uma construção de significado. Leitura como construção de significado não implica, no entanto, um "vale-tudo", como aponta Altmayer. Para uma compreensão num sentido dialógico, o contexto situacional (o autor, o contexto local e temporal, o público alvo do texto "original", o contexto sociopolítico, o histórico de publicação e divulgação) precisa ser levado em conta.

Partindo dessas premissas teóricas, faz-se necessário agora a seguinte pergunta: tendo como meta uma melhora da "compreensão do estrangeiro" pelos aprendizes, qual seria então a diferença didática entre o processo de leitura e o processo de tradução na sala de aula de uma língua estrangeira?

\section{A tradução e a "compreensão do estrangeiro"}

Para uma reflexão sobre o possível papel da tradução para a "aprendizagem crítico-reflexiva", deve-se mencionar a dissertação de mestrado de Luiz E. S. Hargreaves, intitulada Além da língua: tradução e consciência crítica de cultura no ensino de língua estrangeira (2004), na qual o autor reflete sobre a tradução no ensino de línguas estrangeiras a partir da premissa de que se trata de um "processo cultural" (HARGREAVES, 2004, p. 41) ${ }^{9}$. Embora não concordemos com as referências indiscriminadas que o autor faz a estudiosos da tradução de vertentes teóricas muito diversas, sem explicar ou justificar essa justaposição (por exemplo, de teóricos como Rosemary Arrojo, George Steiner, Eugene Nida e Katharina Reiss), vemos nesse trabalho o primeiro passo para um diálogo entre a tradução, os estudos culturais e o ensino de língua estrangeira, considerando a tradução uma "atividade comunicativa" e altamente complexa que deveria ser "integrada no resto do programa de ensino" de línguas estrangeiras (HARGREAVES, 2004, p. 59). É importante ressaltar que se trata de um olhar acerca da tradução muito diferente daquele que marcava o método de

\footnotetext{
${ }^{9}$ Rosângela L. T. Checchia (2002) na sua dissertação de mestrado $O$ retorno do que nunca foi: o papel da tradução no ensino do inglês como língua estrangeira também menciona, embora perifericamente, a relação entre tradução e cultura.
} 
gramática e tradução, sobretudo por refletir sobre o processo tradutório e suas possíveis implicações para uma maior "consciência cultural" dos aprendizes - diferentemente de abordagens mais tradicionais que se concentravam no produto de tradução, entendendo o ato de traduzir como uma atividade meramente linguística.

Hargreaves parte da premissa da "indivisibilidade" entre língua, cultura e tradução (2004, p. 34) e argumenta que "nenhum processo de aquisição ou aprendizagem de outra língua deverá tentar excluir um desses elementos” (2004, p. 34). De acordo com esse autor, "[q]uando se fala em dificuldades da tradução ou de elementos intraduzíveis, trata-se, em geral, de aspectos culturais" (2004, p. 39). Se a "mera" leitura já pode causar estranhamento (JANZEN, 2007), na tradução, as diferenças saltam ainda mais aos olhos, o estranhamento com a diferença e/ou a semelhança é maior. O seguinte comentário de Hargreaves, por exemplo, aponta a diferença entre leitura e tradução nesse sentido, argumentando em favor do uso da tradução em sala de aula:

[...] o contraste cultural gerado pela atividade de tradução é ainda mais eficaz devido ao fato de ser resultado da própria produção do aprendiz. A simples comparação entre elementos culturais distintos apresentados pelo professor ou autor do material didático torna o aprendiz um participante passivo no processo de aquisição, o que limita os resultados e aumenta a crítica à outra cultura. Por outro lado, se essa percepção é fruto do trabalho do próprio aprendiz, essa consciência é internalizada e finca raízes mais profundas. (HARGREAVES, 2004, p. 55)

Tanto a leitura de textos em língua estrangeira como a tradução (independentemente da sua "direção", ou seja, da língua materna para a língua estrangeira ou da língua estrangeira para a língua materna) são atividades de interpretação do estrangeiro ${ }^{10}$. No entanto, dependendo da estratégia de leitura utilizada, a leitura pode procurar evitar o estranhamento. Quando, porém, a comparação entre os "padrões culturais de interpretação" da língua materna e da estrangeira constitui o objetivo didático desejado, a tradução pode se revelar como um caminho mais eficiente que a leitura e contribuir para uma maior conscientização cultural (cultural awareness).

A partir disso, pode-se pensar, por exemplo, sobre a possibilidade de uma atividade tradutória em sala de aula que aborde os diferentes "estilos conversacionais"

\footnotetext{
${ }^{10}$ Nesse sentido, não concordamos integralmente com o comentário de Hargreaves de que, na leitura, o aprendiz seria apenas um "participante passivo no processo de aquisição" (2004, p. 55).
} 
(MEIRELES, 2005) de falantes nativos de alemão e brasileiros ou outros aspectos pragmáticos e/ou culturais. Em outros momentos, a intenção didática pode ser a reflexão não apenas de diferenças, mas também de semelhanças entre os contextos culturais em questão. Num curso de alemão como língua estrangeira no nível A1, no Centro de Línguas e Interculturalidade (Celin), da UFPR, já desenvolvemos algumas atividades de tradução de diálogos cujo objetivo principal foi conscientizar os aprendizes em relação às diferenças no trato formal e informal entre brasileiros e alemães. Pudemos observar que, durante as explicações por parte da professora e durante a leitura de diálogos em língua estrangeira, as diferenças pareciam não causar dificuldade de compreensão. No entanto, durante a tradução de alguns diálogos, as dificuldades e ambiguidades se tornaram mais claras e as discussões a seu respeito mais instigantes - os dois diferentes "padrões culturais de interpretação" tornaram-se o centro dessas discussões.

Além de realizar atividades que envolvem a atividade tradutória por parte dos aprendizes, é possível também comparar diferentes traduções (ou feitas pelos próprios aprendizes ou já publicadas) em sala de aula. Nesse sentido, nos referimos também à argumentação de Claudia S. Dornbusch, que salienta - embora na esfera dos estudos literários propriamente ditos - que a "contraposição de várias traduções de uma mesma obra, por exemplo, pode incitar um enriquecedor diálogo intercultural, na medida em que se observam as variantes pelas quais optaram os tradutores" $(2005$, p. 73$)$.

\section{Conclusão}

Tanto a leitura quanto a tradução devem ser vistas, no âmbito do ensino de línguas estrangeiras, não apenas como habilidades comunicativo-pragmáticas, mas como processos fundamentais para desenvolver e/ou melhorar a "compreensão do estrangeiro" nos moldes propostos por Altmayer. No caso da tradução, aquilo que faz essa atividade relevante e produtiva para a sala de aula não é o produto que dela resulta, mas o próprio processo tradutório que envolve tanto questões linguísticas quanto culturais. Nesse sentido, levando em consideração as características do ensino de línguas estrangeiras no Brasil (perfil monolinguístico dos aprendizes, posição geográfica distante dos países de língua alvo, poucas possibilidades de contato direto 
com falantes nativos da língua alvo), a tradução pode ocupar um papel relevante em sala de aula tanto a partir de um foco no seu aspecto pragmático (como previsto no Quadro Europeu Comum), quanto num sentido mais amplo, como possibilidade de os aprendizes se ocuparem com questões eminentemente culturais e familiarizarem-se com os "padrões culturais de interpretação" de uma comunidade comunicativa alheia.

\section{Referências}

ALTMAYER, Claus. Kultur als Hypertext: $Z u$ Theorie und Praxis der Kulturwissenschaft im Fach Deutsch als Fremdsprache. München: Iudicum, 2004.

ARROJO, Rosemary. O signo desconstruído: implicações para a tradução, a leitura e o ensino. Campinas, SP: Pontes, 1992.

BLUME, Rosvitha Friesen. O diálogo intercultural como processo hermenêutico no ensino de língua estrangeira: uma análise da obra didática "Themen Neu”. 1997. Dissertação (Mestrado de Linguística) - Centro de Comunicação e Expressão, Universidade Federal de Santa Catarina, Florianópolis (SC), 1997.

BOHUNOVSKY, Ruth; ZINK B., Carmen. Deutsch für Brasilianer: Begegnungen mit dem Fremden als Vorbereitung für interkulturelle Kompetenz. Zeitschrift für Interkulturellen Fremdsprachenunterricht, vol. 10, n. 3, 2005. Disponível em: <http://zif.spz.tu-darmstadt.de/jg-10-3/beitrag/BohunovskyBolognini2.htm>. Acesso em: 25 maio 2009.

CHECCHIA, Rosângela Lopes Toledo. O retorno do que nunca foi: o papel da tradução no ensino de inglês como língua estrangeira. 2002. Dissertação (Mestrado em Linguística Aplicada) - Departamento de Línguas Estrangeiras e Tradução, Universidade de Brasília, Brasília, 2002.

CHRIST, Herbert. Fremdverstehen in der Praxis interkulturellen Lernens im Fremdsprachenunterricht. In: BREDELLA, Lothar; CHRIST, Herbert (Org.). Fremdverstehen und Interkulturelle Kompetenz. Tübingen: Gunter Narr, 2007. p. 51-77.

DENGSCHERZ, Sabine. Sprachennetze knüpfen: Warum Sprachvergleich beim Lernen hilft. ÖDaF-Nachrichten, Viena, vol. 24, n. 2, p. 47-54, 2008.

DORNBUSCH, Claudia S. A literatura alemã nos trópicos: uma aclimatação do cânone nas universidades brasileiras. São Paulo: Annablume, 2005.

Fremdsprache Deutsch - Übersetzen im Deutschunterricht. Zeitschrift für die Praxis des Deutschunterrichts. Stuttgart: Klett; Heft 23, 2000. 
GLABONIAT, Manuela; MÜLlER, Martin; RUSCH, Paul. Profile Deutsch: Gemeinsamer Europäischer Referenzrahmen. Berlin, München: Langenscheidt, 2005.

HABERMAS, Jürgen. Theorie des kommunikativen Handelns. Frankfurt am Main: Suhrkamp, 1981.

HARGREAVES, Luiz Eduardo Saldanha. Além da língua: tradução e consciência crítica de cultura no ensino de línguas estrangeiras. 2004. Dissertação (Mestrado em Linguística Aplicada) - Departamento de Línguas Estrangeiras e Tradução, Universidade de Brasília, Brasília, 2004.

JANZEN, Henrique E. Aproximações pedagógicas e interculturais possíveis no ensino de literatura estrangeira. Línguas \& Letras. Cascavel, vol. 8, n. 14, p. 247-258, 2007.

LEUPOLD, Eynar. Landeskundliches Curriculum. In: BAUSCH, Karl-Richard; CHRIST, Herbert; KRUMM, Hans-Jürgen. (Orgs.). Handbuch Fremdsprachenunterricht. Tübingen: Gunter Narr, 2007. p. 127-133.

MEIRELES, Selma. Estilo conversacional, interculturalidade e língua estrangeira. Pandaemonium Germanicum. São Paulo, FFLCH/USP, n. 9, p. 311-326, 2005.

PRAXEDES, Carmem. Quadro Comum Europeu de ensino-aprendizagem e avaliação de línguas - o que falta ao Cone Sul para seguir este exemplar modelo de integração multicultural? 2008. Disponível em: <http://www.filologia.org.br/revista/40suple/quadro_comum_europeu.pdf >. Acesso em: 25 maio 2009.

SURKAMP, Carola. Fremdes spielerisch verstehen lernen: Zum Potenzial dramatischer Texte und Zugangsformen im Fremdsprachenunterricht In: BREDELLA, Lothar, CHRIST, Herbert (Org.). Fremdverstehen und interkulturelle Kompetenz. Gießener Beiträge zur Fremdsprachendidaktik. Tübingen: Gunter Narr, 2007. p. 133-147.

WELKER, Herbert Andreas. Traduzir frases isoladas na aula de língua estrangeira: por que não? 2004. Disponível em: <www.unb.br/il/let/welker/tradfras.doc>. Acesso em: 11 dez. 2008. 